\section{The unavoidable costs of frailty: a geriatric perspective in the time of COVID-19}

\author{
Maria Cristina Polidori, ${ }^{1}$ \\ Stefania Maggi, ${ }^{2}$ \\ Francesco Mattace-Raso, ${ }^{3}$ \\ Alberto Pilotto ${ }^{4}$ \\ ${ }^{1}$ Professor of Geriatrics and Head \\ Ageing Clinical Research, Department \\ Medicine II, University Hospital of \\ Cologne and Cologne Excellence Cluster \\ on Cellular Stress Responses in \\ Aging-associated Diseases, CECAD, \\ University of Cologne, Germany; \\ ${ }^{2}$ Director Aging Section, National \\ Research Council (CNR), Padova, Italy; \\ ${ }^{3}$ Head Division of Geriatrics, \\ Department of Internal Medicine, \\ Erasmus MC University Medical Center, \\ Rotterdam, The Netherlands; \\ ${ }^{4}$ Director Department Geriatric Care, \\ Orthogeriatrics and Rehabilitation, \\ Galliera Hospital, Genova; Professor of \\ Geriatrics, Department of \\ Interdisciplinary Medicine, University of \\ Bari, Italy
}

The world is facing speechless one of the most feared, greatest catastrophes for human beings. Despite better healthcare systems, despite warnings through similar situations ${ }^{1}$ and even documented threats, ${ }^{2}$ as the COVID-19 pandemic hit, it found us largely unprepared. It offered to us on a silver tray the fragility of mankind. And once again, but this time in a particularly overwhelming way, the most vulnerable part of the world population is mowed down: older persons.

Indeed, recent data from the Italian Istituto Superiore di Sanità showed that COVID-19 is more lethal in older subjects: in Italy, at the date of March 17, 2020, the overall case-fatality rate was $7.2 \%$ and $96.4 \%$ of died patients had more than 60 years. When data were stratified by age groups, individuals aged 70 years or older represent $35.5 \%$ of cases, while subjects aged $\geq 80$ years were $52.3 \% .^{3}$ These data confirm once again that the older generation payed the highest price in time of crisis.

An entire generation is being mowed down, said on March 21 2020 Sergio Mattarella, the President of Italian Republic. This generation put at horrendous threat now by SARS-CoV-2 worldwide is the generation of persons which geriatri- cians chose once to dedicate their professional life to.

As geriatricians, we have learned and are used to accompany our patients through very tough phases during life, sometimes through the end stage of their lives. As geriatricians, we often have to manage situations which have been built upon many decades of a life with unhealthy lifestyles. But most of all, as geriatricians we deal every day with fragility and vulnerability: that condition called frailty mirroring on a small scale - a single person, our individual patient - the large-scale vulnerability of mankind.

By education and training, specialists in ageing medicine deal everyday with all the issues dramatically impacting clinical decision making during the COVID-19 pandemics. First of all, in fact, triaging. One of the main scopes of Geriatrics is to identify patients maximally benefiting of goal-oriented, tailored, multidisciplinary personalized interventions; to identify patients at risk of poor outcomes, indeed, the frail persons. Conversely, a critical ethical issue is when to suspend treatment, when to give the last infusion. Today, during the COVID-19 epidemics, the triaging of patients in the hospitals should be based mostly on frailty criteria. ${ }^{4}$ There is a strong rationale for this as well as for the rapid development of prospective protocols with prognostic tools based operationally on a multidimensional approach to frailty ${ }^{5}$ like the Multidimensional Prognostic Index (MPI) ${ }^{6}$ Although patients with COVID-19 are at risk of poor prognosis if affected by multimorbidity, this information is not enough, as type of comorbidity clusters is far more predictive than number of comorbidities itself.7 Indeed, crucial for prognosis in older patients are, besides disease-specific determinants and polypharmacy, also functional, physical, and psychosocial factors, that can be best addressed by multidimensional tools. ${ }^{8}$

Frailty is an age-related clinical condition characterized by a decline in physiological capacity across several organ systems, with a resultant increased susceptibility to stressors. ${ }^{9}$ In this context, frailty means diminished organ reserve including that of the lung, which is dreadful in a viral disease affecting the respiratory tract. As the organism ages, there is a decline in the elasticity of the bony thorax, loss of muscle mass and weakening of muscle of respiration with consequent reduced mechanical advantage, there is a lower responsiveness in the central nervous system as well as diminished alveolar gas exchange surface area. Age-related changes of the respiratory system induce therefore a reduced pulmonary reserve which leads to impaired
Correspondence: Maria Cristina Polidori.

E-mail: maria.polidori-nelles@uk-koeln.de

Key words: COVID-19; frailty; geriatrics.

Received for publication: 27 March 2020.

Accepted for publication: 27 March 2020.

This work is licensed under a Creative Commons Attribution-NonCommercial 4.0 International License (CC BY-NC 4.0).

${ }^{\circ}$ Copyright: the Author(s), 2020

Licensee PAGEPress, Italy

Geriatric Care 2020; 6:8989

doi:10.4081/gc.2020.8989

cough strength and, at the end, a reduced clearance of particles from the lung through the mucociliary elevator. ${ }^{10}$ Many complex changes in immunity with aging contribute to increased susceptibility to infections including a less robust immune response from both the innate and adaptive immune systems. ${ }^{11}$

Considering all of these age-related changes to the lungs, pulmonary disease has significant consequences for the aging population. Chronic lower respiratory tract disease is the third leading cause of death in people aged 65 years and older, ${ }^{12}$ with the presence of obstructive pulmonary disease being, after aging, one of the major causes of poor COVID-19-related prognosis together with obesity. Frailty means also, at a biomolecular level, inflammaging, immunosenescence, malnutrition, increased biological age, reduced oxygen uptake and altered energy balance, ${ }^{5}$ all factors substantially contributing to failure to thrive in general and in particular to the low response to intensive treatment in COVID positive patients. Frailty means atypical disease presentation due to the quick involvement of weakest links of the aging organism such as the central nervous system or the continence system. And frailty means other COVID-19-related aspects, too: the social issue, with the important role of physical contact and warmth in the spread of the disease on one side and the psychological consequences of isolation on the other side; and the sex issue, as the malefemale health-survival paradox, for which older women are frailer but in-hospital death is higher for men ${ }^{13}$ might be confirmed even in this pandemics.

The community of Geriatricians is heartbroken over the loss of an incredible number of unique persons, unique source of humanity and wisdom, so important in this phase of the history. The only thing we can do at this time is sharing - doctors, beds, equipments, knowledge. ${ }^{14}$ The only thing 
we can do at this time is offering all the expertise we collected since the early years of the past century, when it was recognized that older patients needed specialized care beyond organ medicine.

My inspiration and my passion will always come from my older patients.

One day I hope to be like them; when that day comes, I hope that my doctor will be a geriatrician. William R, Hazzard WR,

I am a Geriatrician; $2004^{15}$

\section{References}

1. Gates B. The next outbreak? We are not ready. TED Conference LLC "Ebola", April 3rd, 2015. Available from: https:// m.youtube.com/watch?v=6Af6b_wyiwl

2. Menanchery VD, Yount Jr BL, Debbink $\mathrm{K}$, et al. A SARS-like cluster of circulating bat Coronaviruses shows potential for human emergence. Nature Med 2015;21:1508-13.

3. Onder G, Rezza G, Brusaferro S. Casefatality rate and characteristics of patients dying in relation to COVID-19 in Italy. JAMA 2020, Published online March 23, 2020.
4. National Institute for Health and Care Excellence (NICE). COVID-19 rapid guideline: critical care. NICE Guideline [NG159] - Published date: March 2020.

5. Pilotto A, Custodero C, Maggi S, Polidori MC, Veronese N, Ferrucci L. A Multidimensional Approach to Frailty in Older People. Ageing Res Rev 2020;60:101047.

6. Cruz-Jentoft AJ, Daragjati J, Fratiglioni L, et al.; on behalf of MPI_AGE Investigators. Using the Multidimensional Prognostic Index (MPI) to improve cost-effectiveness of interventions in multimorbid frail older persons: results and final recommendations from the MPI_AGE European Project. Aging Clin Exp Res 2020 [Epub ahead of print]. doi:10.1007/ s40520-020-01516-0.

7. Zucchelli A, Vetrano DL, Grande G, et al. Comparing the prognostic value of geriatric health indicators: a populationbased study. BMC Med 2019;17 [Epub ahead of print]. doi:10.1186/s12916019-1418-2.

8. Pilotto A, Cella A, Pilotto A, et al. Three Decades of Comprehensive Geriatric Assessment: Evidence Coming From Different Healthcare Settings and Specific Clinical Conditions. J Am Med Dir Assoc 2017;18:192.e1-e11.
9. Dent E, Martin FC, Bergman H, et al. Management of frailty: opportunities, challenges, and future directions. Lancet 2019;394:1376-86.

10. Skloot GS. The effects of aging on lung structure and function. Clin Geriatr Med 2017;33:447-57.

11. Oh S-J, Lee J-K, Shin OS. Aging and the immune system: the impact of immusenescence on viral infection, immunity and vaccine immunogenicity. Immune Netw 2019;19:e37.

12. World Health Organization. WHO: GBD 2017 Mortality Collaborators. Global, regional, and national age-sexspecific mortality and life expectancy, 1950-2017: a systematic analysis for the Global Burden of Disease Study 2017. Lancet 2018;392:1684-735.

13. Veronese N, Siri G, Cella A, et al. on behalf of MPI_AGE Investigators. Older women are frailer, but less often die than men: a prospective study of older hospitalized people. Maturitas 2019;128:81-6.

14. Harari YN. The world after coronavirus. The Financial Times. March 20, 2020.

15. Hazzard WR. I am a Geriatrician. J Am Geriatr Soc 2004;52:161. 